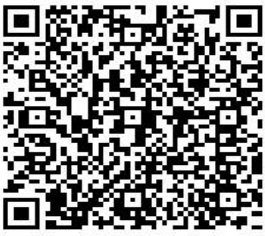

\title{
TREND AND PATTERN OF AGED SEX RATIO IN KARNATAKA: A GEOGRAPHICAL ANALYSIS
}

Sowmyashree $K L^{*}$ and B N Shivalingappa**

Abstract
Sex ratio in Karnataka is becoming adverse to women, but is favourable
for women, when aged sex ratio is noticed. It is because of difference
in the life expectancy of different sexes, which leads to feminization at
older ages. It shows that female aged population has been increasing
drastically than their male counter-part. As a result of this trend the
aged sex ratio has been at a faster rate increasing decade by decade
but widely differs among different taluks or different spatial units. It is in
this context, the present paper is an endeavour to analyse the spatio-
temporal patterns of old age sex ratio in Karnataka taking taluk as an
unit of analysis based on secondary data. Choropleth technique is
used for mapping. The study reveals that the state has higher elder sex
ratio than the general sex ratio, from 1971-2001.




\section{Introduction}

The sex composition of population is conveniently expressed by sex ratio; most common practice is to describe it as "the number of females per 1000 males or viz - a viz. The balance between the sexes is an important aspect of population structure, because all other population characteristics may be influenced by the ratio between the sexes and it is also an important indicator of gender disparity in a society. However the sex composition of the present population is determined by the life expectancy, trends of birth, death rates and migration.

Sex ratio in Karnataka is becoming adverse to women, but is favourable for women, when aged sex ratio is noticed. It is because of difference in the life expectancy of different sexes, which leads to feminization at older ages. It shows that female aged population has been increasing at a faster rate than their male counter-part. As a result of this trend the aged sex ratio has been rapidly increasing decade by decade though widely differs among different taluks or different spatial units.

It is attempted in this paper to analyse the spatio - temporal pattern of sex ratio in Karnataka taking taluk as unit of analysis. The temporal trend is analysed for a period of 40 years from 1971 to 2001 and spatial analysis is also confined to the same period. The present study is based entirely on secondary data taken from census reports and choropleth technique is used for the analysis of the data.

The Aged population is defined as those who are 60 years and above, which is normally adopted in most of the studies and the aged sex ratio means the ratio between male and female elders.

\section{Study area}

Karnataka state lies in the south-western part of the peninsular India. The state Karnataka's extends for about $750 \mathrm{Kms}$ from north to south and about $400 \mathrm{Kms}$ from east to west. Total land area is $1.91 .791 \mathrm{sq} \mathrm{kms}$. It accounts for $5.83 \%$ of the total area of the country (32.88 lakhs sq Kms) and ranks 8th among the major states of India in terms of size. As per the 2001 census the state's population is 5.27 crores out of which 2.68 crores are males and 2.58 crores are females.

Karnataka occupies 9th place in India with regard to population. In 2001 state has 27 districts, 175 Taluks, 745 Hoblis, and 254 urban centres. 


\section{Discussion}

\section{The trend of General and Aged Sex ratio of Karnataka - A Comparative}

Analysis:

It is the component of demographic study with which one can identify the relatively strength of male and female population. In this section it is attempted to compare the general and aged sex ratio of the state from 1971 to 2001 . There is a positive relationship between total and aged sex ratio (Correlation Co-efficient - 0.8).

Table.1 General and Aged Sex ratio of Karnataka

\begin{tabular}{|c|c|c|}
\hline Years & General Sex ratio & Aged Sex ratio \\
\hline 1971 & 957 & 959 \\
1981 & 963 & 1011 \\
1991 & 960 & 997 \\
2001 & 964 & 1111 \\
\hline
\end{tabular}

Source: Census of India

Chart. 1 General and Aged Sex ratio of Karnataka

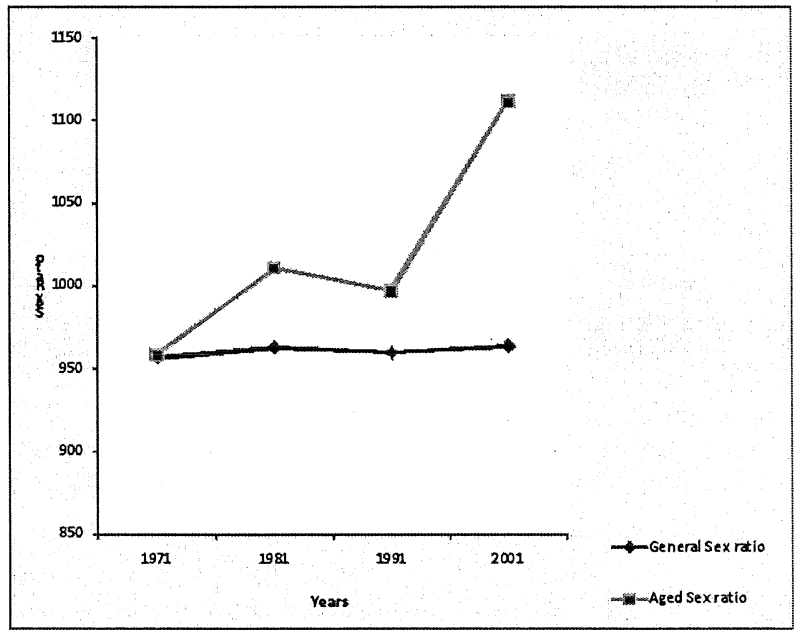


The table and chart. 1 depicts that both general and old age sex ratios have been fluctuating from 1971 to 2001 and the significant point is that, compared to general sex ratio (964) elderly sex ratio is much above with 1111 female elders per 1000 males according to 2001. But the temporal trend of aged sex ratio is changing rapidly than that of general sex ratio (chart.1). Both the ratios were less and almost similar (957 for general sex ratio and 959 for aged sex ratio) in 1971 increasing, after words though these was slight decline in 1991, showed improvement in 2001. However, the gap between the general and old age sex ratio of the state has been getting wider thus reflecting the fact that females are predominant at older ages, leading to feminization at older ages.

It is mainly determined by differential life expectancy of the different sexes (female life expectancy was more comparing to male life expectancy). The male life expectancy grew from 50 years in 1971 to 63.1 years in 2001 where as the female life expectancy has increased from 49 years to 66.7 years in the same period (table2). As result of this female population is growing rapidly decade by decade leading to high sex ratio at older ages.

Table. 2 Life expectancy by gender and Aged sex ratio

\begin{tabular}{|c|c|c|c|}
\hline \multirow{2}{*}{ years } & \multicolumn{2}{|c|}{ Life expectancy (Years) } & Aged sex ratio \\
\cline { 2 - 3 } & Male & Female & \\
\hline 1971 & 50 & 49 & 959 \\
2001 & 63.1 & 66.7 & 1111 \\
\hline
\end{tabular}

Source: Hand book of Karnataka 2001

\section{Pattern of General and Aged Sex ratio of Karnataka: A Geographical Analysis:}

In Karnataka, both the general and old age sex ratio has been unfavourable to females during 1971 and after words it started increasing especially at older ages. But it widely differs from taluk to taluk of Karnataka.

In Karnataka state also it is found very clearly that there are wide differences in the sex ratio of the both overall and elderly population. Taluks of high Aged sex ratio (above 1000 females per 1000 males) have increased nearly three-fold from 59 taluks in 1971 to 157 taluks in 2001 and around $90 \%$ of the taluks have high female population in 2001 (fig. 1), while taluks of lower sex ratio ranging below 900 have tremendously decreased from 80 taluks to only one taluk; there by bringing to light the fact that the females have higher life expectancy than the males, which leads to high old age sex ratio in 2001 . Therefore this high sex ratio considered as a serious matter by the demographers and social scientists including geographers. 
Table. 3 Spatio - Temporal variation in the range of General and Old age sex ratio of the taluks of Karnataka state

\begin{tabular}{|l|c|c|c|c|c|c|c|c|}
\hline \multirow{3}{*}{ Ranges } & \multicolumn{3}{|c|}{ General sex ratio* } & \multicolumn{3}{c|}{ Old age Sex ratio** } \\
\cline { 2 - 8 } & \multicolumn{2}{|c|}{1971} & \multicolumn{2}{|c|}{2001} & \multicolumn{2}{c|}{1971} & \multicolumn{2}{c|}{2001} \\
\cline { 2 - 8 } & $\begin{array}{c}\text { No. of } \\
\text { Taluks }\end{array}$ & $\%$ & $\begin{array}{c}\text { No. of } \\
\text { Taluks }\end{array}$ & $\%$ & $\begin{array}{c}\text { No. of } \\
\text { Taluks }\end{array}$ & $\%$ & $\begin{array}{c}\text { No. of } \\
\text { Taluks }\end{array}$ & $\%$ \\
\cline { 2 - 8 }$<900$ & 9 & 5 & 5 & 3 & 80 & 46 & 1 & 1 \\
$900-1000$ & 146 & 83 & 146 & 83 & 35 & 20 & 17 & 10 \\
$>1000$ & 21 & 12 & 25 & 14 & 59 & 34 & 157 & 89 \\
\hline
\end{tabular}

Source: * census of India $1971 \& 2001{ }^{* *}$ computed by the authors

An analysis of table3 pertaining to the number of taluks in three ranges of elders and general sex ratio over time indicates that number of taluks in higher sex ratio has gone up ( 59 to 157 for elder sex ratio and 21 to 25 taluks for general sex ratio) drastically from 1971 to 2001 in the state, but on the contrary number of taluks in lower sex ratio has gone down from 9 to 5 in case general sex ratio and 80 to only one in case of old age sex ratio in the same period. In the range between 9001000, the number remains same for overall sex ratio, but decreased from 35 to 17 for aged sex ratio.

\section{Areas of High Aged Sex ratio (>1000)}

The area of high aged sex ratio stretches over 59 (34\%) taluks in 1971 and it increased to 157 (89\%) taluks in 2001 where female population exceed 1000 male population and eight of these districts (1971) are located in southern and coastal part of the state, viz., Alur (1 103 for old age and 993 for general sex ratio), Channarayapatna (1007 for old age and 1023 for general sex ratio), K.R.Pete (1022 for old age and 1015 for general sex ratio), Udupi ( 1107 for old age and 1151 for general sex ratio), Daksina kannada (1139 for old age and 1028 for general sex ratio), Karkala (1074 for old age and 1043 for general sex ratio), Coondapura (1219 for old age and 1117 for general sex ratio) and one taluk namely Karvara (1233 for old age and 1041 for general sex ratio) and remaining 51 taluks are concentrated in Northern Karnataka and Hyderabad Karnataka (taluks of Bagalkote, Raichur, Gulbarga, Bijapura and Dharwadh districts) and Badami taluk has first rank in the aged sex ratio (1418 aged sex ratio and 1005 for general sex ratio). The high Aged sex ratio in these areas may be because of higher general sex ratio in these areas which leads to high old age sex ratio. 


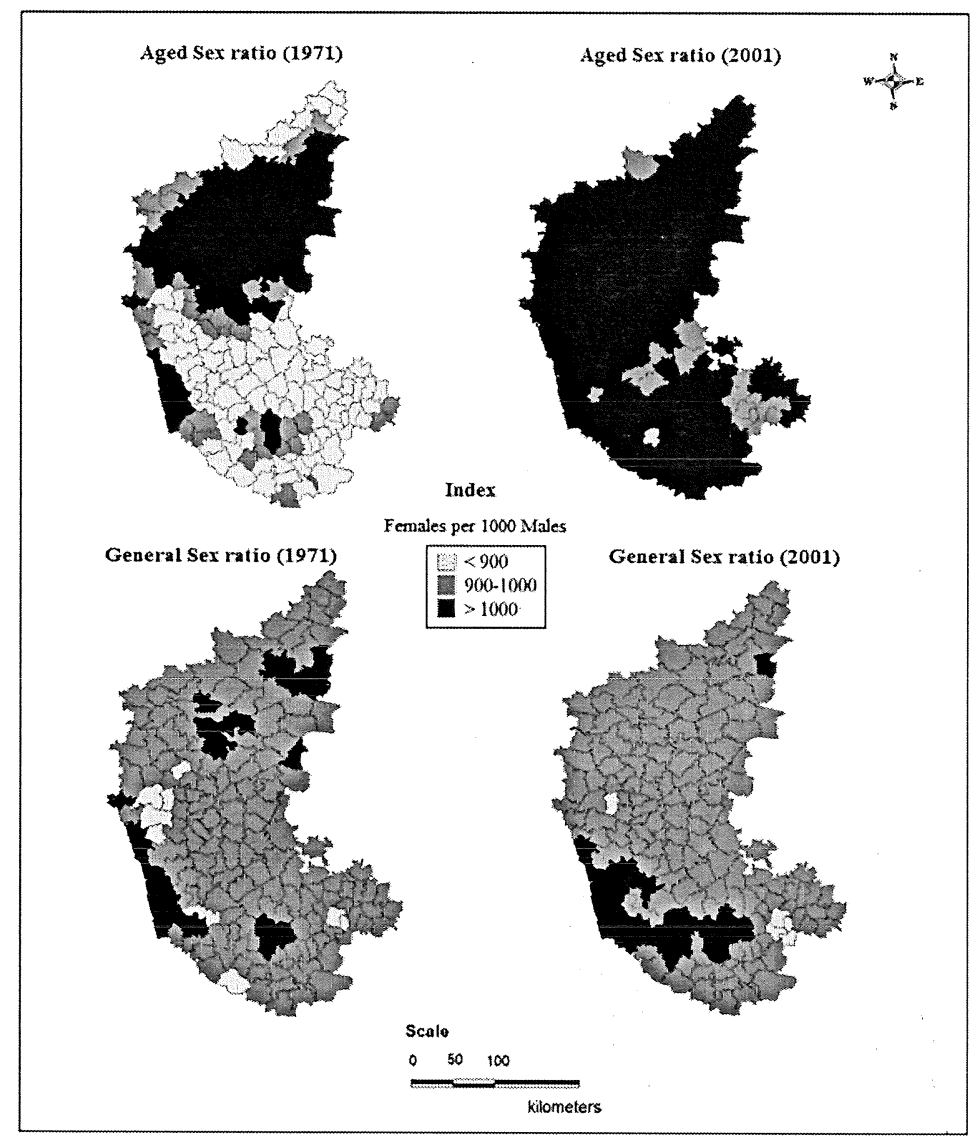

Fig.1 Aged and General sex ratio of Karnataka State (1971 and 2001)

Further the area of higher aged sex ratio in 2001 stretches over 157 taluks covering around $89 \%$ of the total taluks except few taluks in Bangalore, Tumkur etc remaining all the taluks have more than 1000 female elders per thousand male elders. It shows the areas of high aged sex ratio is larger than low aged sex ratio in 2001 , it reveals that the intensity of the process of female elders population growth, which is more compared to their male counter-part.

\section{Areas of Moderate Aged Sex ratio (900-1000)}

The sex ratio of aged population in the range 900 - 1000 represents the medium sex ratio. The medium aged sex ratio has been found in 35 taluks; covering $20 \%$ of 
the total taluks in 1971 and it decreased to 17 taluks (10\%) in 2001. These taluks are mainly concentrated in few taluks in coastal, northern and south Karnataka (Few taluks in Chamarajanagara, Mandya, Tumkur, Hassan, Dakshin Kannada, Kolar, Davangere, Uttara Kannada, Bijapura etc.) in 1971 and in 2001 aged sex ratio is noticed in 17 districts, covering only $10 \%$.

Further general sex ratio is concentrated 146 taluks both in 1971 and 2001.

\section{Areas of low Aged Sex ratio (<900)}

In 80 taluks of southern Karnataka (of these 7 taluks are located in Hyderabad karnataka viz. Indi, Bidar, Afzalpura, Alland, Basavkalyana, Bhalki and Santapur) have aged sex ratio does not exceed 900 females per 1000 male elders in 1971. General sex ratio also decreased from 7 taluks in 1971 to 5 taluks in 2001.

Finally lower aged sex ration in 2001 is found in only one taluk namely Arkalgud (875). It shows that the high old age sex ratio has concentrated in all the taluks of Karnataka state. It reveals that the sex ratio was more in older ages leading to feminization at older ages.

It has been noticed that (Table. 3 and Fig. 1) in high sex ratio has been increasing both general and aged population, especially in old age sex ratio increasing at faster rate compared to general sex ratio, while low sex ratio has been declining in both general and aged population and medium sex ratio is remaining same for general sex ratio in both the decades, but medium aged sex ratio has decreased from 1971 to 2001 .

\section{Conclusion}

The analysis made above lead us to the following conclusions

- Both general and old age sex ratio has been by large increasing from 1971 and main significant point is that, compared to general sex ratio (964) elderly sex has been drastically increasing. Both the ratios were low and almost similar (957 for general sex ratio and 959 for aged sex ratio) in 1971 which has increased in 1981, it (1991) declined and again showing improvement in 2001.

- Aged sex ratio was mainly determined by the life expectancy of the different sexes. The male life expectancy grew from 50 years in 1971 to 63.1 years in 2001 where as the female life expectancy has increased from 49 years to 66,7 
years in the same period (table2). As result of this female aged population is growing rapidly decade by decade leading to higher sex ratio at older ages.

- The area of high aged sex ratio stretches over 59 taluks in 1971 and it has increased to 157 taluks in 2001 where female population exceeds male population and eight of these districts (1971) are located in southern and coastal part of the state and remaining 51 taluks are concentrated in Northern Karnataka and Hyderabad Karnataka.

- The area of higher aged sex ratio in 2001 stretches over 157 taluks covering around $89 \%$ of the total taluks except few taluks in Bangalore, Tumkur etc remaining all the taluks have more than 1000 female elders per thousand male elders.

- The medium proportion of aged sex ratio has been found in 35 taluks; covering $20 \%$ of the total taluks in 1971 and it decreased to 17 taluks (10\%) in 2001.

- In 1971, 80 taluks of Karnataka state did not have more than 900 female elders per 1000 male elders, but it tremendously decreased to one taluk in 2001 namely Arkalgud (875). It shows the old age sex ratio is high with more females per thousand males in all the taluks. It reveals that the sex ratio was more in older ages leading to feminization at older ages.

- Around $89 \%$ of the taluks in 2001 have high old age sex ratio, (Almost all the taluks have high elders sex ratio) having its direct impact on the demand for health, financial and social services for elders from the government and the family. Therefore, it needs appropriate programmes and policies from the government for welfare of the elders, particularly female elders.

\section{Bibliography}

1. Census of India 1971 and 2001.

2. Chandrasekarayya T and Sai Sujatha D (2009), Declining sex ratio in India: Causes and Consequences, Artha Journal of Social Sciences, Vol.8, No.1, Jan-June.

3. Hand book of Karnataka, Karnataka Gazetteer, Government of Karnataka, 2010. (4th edition).

4. Mohan Kumar M.D and Dr. B.N.Shivalingappa (2003), Pattern of Sex ratio: A SpatioTemporal Analysis, National Geographers, Vol.XXXVIII, No.2, July - Dec.

5. Mrs. Swarnjit Mehta and Miss Gurinder Kaur (1983), Rural - Urban Differntials in Sex ratio of Rajasthan, The Indian Geographical journal, Vol.58, No.2, Dec.

6. Randir Singh Sangwan and Sneh Sangwan (2009), Sex ratio: Trends in rural - urban differentials, Transactions (journal of the Institute of Indian Geographers) Vol.31, No.2. 